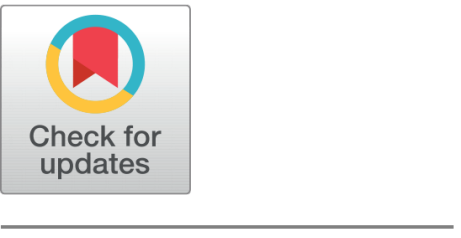

OPEN ACCESS

Received: 31.10 .2020

Accepted: 22.12 .2020

Published: 04.01 .2021

Citation: Alam MR, Islam T, Rahman M, Antor MAAN, Rahman R, Tamanna TA (2020) Sustainable denim fabric washing with post-used rubber shoe sole: An eco-friendly alternative of Pumice stone. Indian Journal of Science and Technology 13(48): 4723-4731. https ://doi.org/10.17485/IJST/v13i48.1974

* Corresponding author.

mti@just.edu.bd

Funding: None

Competing Interests: None

Copyright: (c) 2020 Alam et al. This is an open access article distributed under the terms of the Creative Commons Attribution License, which permits unrestricted use, distribution, and reproduction in any medium, provided the original author and source are credited.

Published By Indian Society for Education and Environment (iSee)

ISSN

Print: 0974-6846

Electronic: 0974-5645

\section{Sustainable denim fabric washing with post-used rubber shoe sole: An eco-friendly alternative of Pumice stone}

\author{
Md. Rubel Alam ${ }^{1}$, Tarikul Islam²*, Mahbubur Rahman ${ }^{3}$, \\ Md. Abdullah Al Noman Antor ${ }^{4}$, Rifat Rahman ${ }^{4}$, Taslima Ahmed Tamanna ${ }^{5}$ \\ 1 Department of Knitwear Manufacturing and Technology, BGMEA University of Fashion and \\ Technology, Dhaka, Bangladesh \\ 2 Department of Textile Engineering, Jashore University of Science and Technology, Jashore, \\ 7408, Bangladesh \\ 3 Department of Textile Engineering, Mawlana Bhashani Science and Technology University, \\ Tangail, 1902, Bangladesh \\ 4 Department of Apparel Manufacturing and Technology, BGMEA University of Fashion and \\ Technology, Dhaka, Bangladesh \\ 5 Department of Textile Engineering, BGMEA University of Fashion and Technology, Dhaka, \\ Bangladesh
}

\section{Abstract}

Background/Objective: Denim fabric is the most versatile dress material and acclaimed the most popular among the young generations due to its trendy looks. Since stone is being vastly used to improve the softness and comfort feeling along with fading effects, but bearing some problems. For instance, stone leads to deterioration of fabric strength, machine wear, and tear, grit deposition in the effluent plant, increasing labor cost to separate the stone powder from the pockets, and also harmful for the expensive laundry machine, etc. On the contrary, post-used rubber shoe soles are thrown or burnt which leads to ozone depletion. Therefore, this study was carried out to mitigate both the existing problems of stone washing and also this endeavor was done to find a suitable alternative of pumice stone. Methods: Washing was continued with both stones, collected rubber shoe sole against enzyme, acid, and bleaching agent. Eventually, washed garments have been tested and compared with the unwashed regular ones, based on visual appearance, degree of shade change, tensile strength, tear strength, abrasion resistance, and weight per unit area, and crimp interchange. Findings: Result reveals the satisfactory values, but the degree of shade changes against acid has poor value due to not having the absorption ability of potassium permanganate $\left(\mathrm{KMnO}_{4}\right)$. Also, the result tells the noise intensity is much lower (68-72 dB) compared to stonewash (89-90 $\mathrm{dB})$. Introducing the aforementioned alternative in denim washing, it shows the perfect results rather than stone one without compromising the trendy looks.

Keywords: Denim fabric; garments washing; physical and mechanical properties; sustainability 


\section{Introduction}

Denim is a sturdy warp-faced cotton twill fabric, which has gained the most popular among the young generations for exposing the western lifestyle ${ }^{(1-5)}$. In that case, denim garments are capturing the ultimate end user more for trendy fashionable look enhanced (Broken-in look/ torn/faded) by washing ${ }^{(3,6,7)}$. Additionally, washing improves visual appearance; softness, conformability, and also fashion looks in denim garments as a first growing sector ${ }^{(2)}$. These washing effects are the result of mechanical and/or chemical processes including stonewash, caustic wash, sandblasting, towel washing, moon washing, and ice washing, scrubbed look washing, damaged look washing, plasma treatment, and ultrasonic treatment and topping ${ }^{(8,9)}$. Traditional stone (volcanic stone having vesicular rough texture) wash is being widely used in the denim industry, which gives a faded look ${ }^{(5)}$, due to the degree of varying size and shape. Pumice stone (volcanic rock) is commonly originated in Indonesia and Turkey, which floats on water, and is hydrophilic.

Although stone is being used vastly in washing, bearing some problems. For instance, stone leads to deterioration of fabric strength, machine wear and tear ${ }^{(5)}$, grit deposition on the environment, and in the effluent plant, increasing labor cost to separate the stone powder from the pockets, wear \& tear for expensive laundry machines, etc. ${ }^{(8,10)}$. So the researchers are trying to get rid of stone by any suitable alternatives ${ }^{(11)}$. To overcome the shortcomings, synthetic stone i.e. plastic, rubber in Portland is the best abrasive ${ }^{(12)}$. Following this loop, concern increasing day by day in the industry, and the use of environmentally friendly, nontoxic, fully-biodegradable enzymes have been increased to a great extent ${ }^{(2,5,13)}$.

On the contrary, the shoe sole is a rubbery material and does not dispose easily on earth. Surprisingly, post-used shoe soles can be seen on the field, roadside, or in the water flow drain which clogs the water flow drain. Moreover, these undammed materials are sometimes burnt, and hence forms carbon-di-oxide, which is a major driving force of global warming by ozone depletion $^{(14-16)}$. Nowadays, it is high time to maintain a circular economy for the well-being of future generations. There are various types of soles used in making footwear. On which, Polyurethane (PU), Rubber, Thermoplastic Rubber (TPR), Leather, Plastic are used significantly in the industry due to having realistic usability.

Washing is the most prominent vertical growing sector. In denim production over the globe, many disadvantages have been found by pumice stone wash. In order to cope with these problems, this endeavor has attempted to up-cyclic rubber shoe sole as a replacement for stone, and measured tensile strength, tearing strength, gram per square meter, abrasion resistance, fabric count, and crimp interchange sound intensity, etc.

\section{Materials and Methods}

\subsection{Materials}

\subsubsection{Garment sample}

The experimental wagon has been covered with a total of seven denim pants, one kept as raw, and also 3 pairs for different washing. $100 \%$ cotton warp-faced (3/1) twill indigo-dyed denim fabrics (GSM-434, EPI-100, PPI-54, $\mathrm{Ne}_{w p}-16 \mathrm{KW}$, and $\mathrm{Ne}_{w f}{ }^{-}$ $12 \mathrm{KW}$ ) have been used to experiment.

\subsubsection{Collection of post-used shoe sole}

It is well known that shoe soles are thrown out and now, small business firms (dust collectors) collect this post used material like water bottle, drum, tyre wheel, and many more thermoplastic polymers for their business interest. Accordingly, a significant amount has been collected and cut into different size shapes by mechanical hacksaw blades as a tone. After cutting, a total of $2.90 \mathrm{~kg}$ has been soaked into $3 \mathrm{~g} / \mathrm{L}(\mathrm{w} / \mathrm{v}$ ) caustic soda mixed water at room temperature for 24 hours. It is illustrated with the same amount of stone taken for this experiment.

\subsubsection{Properties of post-used shoe sole}

In this experiment, we have used a rubber shoe sole due to having the properties of light in weight but sometimes heavy, good tensile/tear strength, good shock-absorbing ability, reusable and recyclable, etc.

\subsection{Methods}

\subsubsection{Washing procedures}

The experimental work has been conducted in Natural Denims Limited, Ashulia, Savar, and Dhaka, Bangladesh with the constant help of the research and innovations team. In the first phase, a total of seven specimens have been taken, then desized with $0.7 \mathrm{~g} / \mathrm{L}$ desizing agent (Eco-size AM), and $0.6 \mathrm{~g} / \mathrm{L}$ detergents (Hostapur WCTH) with $0.2 \mathrm{~g} / \mathrm{L}$ anti-back staining agent 
(Antistain- LP30) at $60^{\circ} \mathrm{C}$ temperature for $30 \mathrm{~min}$. Henceforth, the hot rinsed wash is done at $70^{\circ} \mathrm{C}$ followed by cold water wash.

For enzyme wash with stone, $1.5 \mathrm{~g} / \mathrm{L}$ enzyme, $1 \mathrm{~g} / \mathrm{L}$ anti-back staining agent has been applied at $40^{\circ} \mathrm{C}$ temperature for 30 min. In order to bleach wash with stone, $3 \mathrm{~g} / \mathrm{L} \mathrm{KCI}, 50 \mathrm{~L}$ water put it into the industrial washing machine (Sutlick, Singapore) for $7 \mathrm{mins}$, and then added potassium thiosulphate $2000 \mathrm{~g}$, and starts the machine at $60^{\circ} \mathrm{C}$ temperature for $15-30 \mathrm{~min}$. Again for an acid wash with stone are treated with potassium permanganate for 1 day then used potash $10 \mathrm{~g} / \mathrm{L}$, water $2 \mathrm{~g} / \mathrm{L}$, Sodium meta-bisulfite $\left(\mathrm{Na}_{2} \mathrm{~S}_{2} \mathrm{O}_{3}\right) 150 \mathrm{~g}$ at $60^{\circ} \mathrm{C}$ temperature for $20 \mathrm{mins}$. After every wash, a hydro-extractor machine (Zanussi, Roaches, England) has been used for $2 \mathrm{~min}$ with $180 \mathrm{rpm}$ to remove excess amount water at $88^{\circ} \mathrm{C}$ temperature, and then dried in a dryer (Opti-Dry, Roaches, England) at $75^{\circ} \mathrm{C}$ for 35-40 min. Correspondingly, the same treatment with previous materials has been done with shoe sole instead of stone for three garments. Here, one desized garment has been kept as raw denim for comparing the properties with different washed samples.

\subsubsection{Testing standards}

For evaluation of different material properties on raw and washed samples the testing methods, gathered in Table 1, are used in the research.

Table 1. Test standards

\begin{tabular}{ll}
\hline Test Name(s) & Test Standards \\
\hline Atmospheric conditioning & ASTM D1776 \\
Tensile strength (US Grab test) & ASTM D 5034 \\
Tearing strength & ASTM D1424 \\
Fastness to laundering & AATCC-61 \\
GSM & ASTM D3776 \\
Abrasion resistance & ASTM D 4966-98 \\
Crimp interchange & ASTM D 3883 \\
Fabric count & ASTM D 3775-08 \\
\hline
\end{tabular}

Meanwhile, noise intensity has been measured by android application (Decibel - Threshold Sound Meter (Noise Levels)) directly.

\section{Results and Discussion}

\subsection{Change of color shade}

Colorfastness to washing of studied samples has been visually assessed by the greyscale and shown in Figure 2 . Apparent eyes see, Enzyme (stone) and Enzyme (sole) have scored as 3, which indicates average value. The color change scale consists of nine pairs of grey colored chips, from grades 1 to 5 (with four half steps). Grade 5 represents no change and grade 1 depicts severe change in some standards. On the other side, Acid (stone) gains scored as 1 which indicates poor, and also Acid (sole) scores as 2 which indicates Moderate. Bleach (stone), and Bleach (sole) both have scored as 1 which indicates poor value.

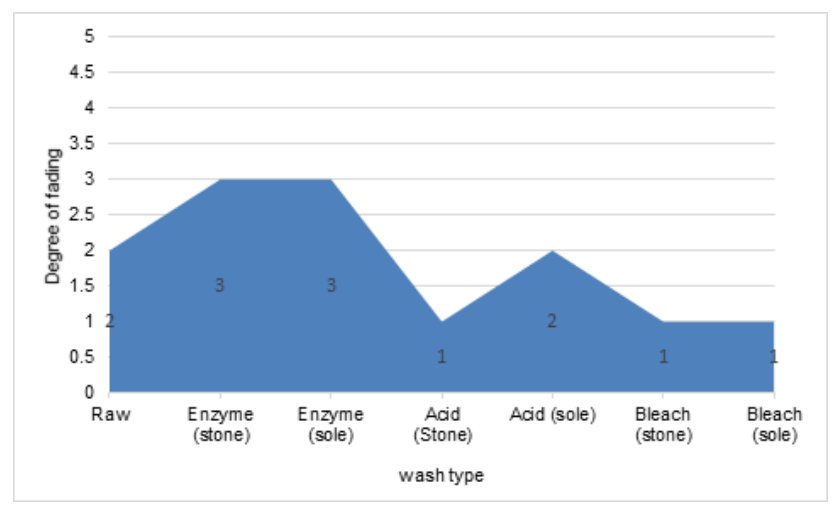

Fig 1. Colorfastness to washing of denim fabrics 
From Figure 1, it is seen that both Enzyme (stone), Enzyme (sole) with Bleach (stone), and Bleach (sole) are identically the same, so sole can be applied effectively instead of stone, but it is not possible to use sole instead of stone in acid wash, because sole does not absorb Potassium permanganate, which creates an effect in washing but the stone did that.

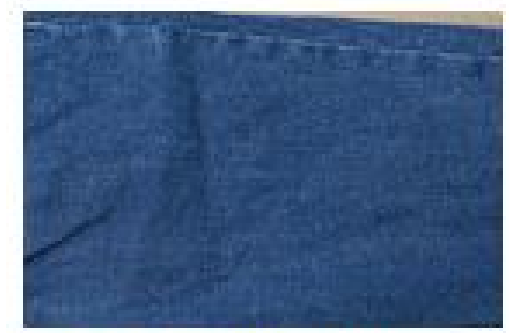

Enzyme (Stone)

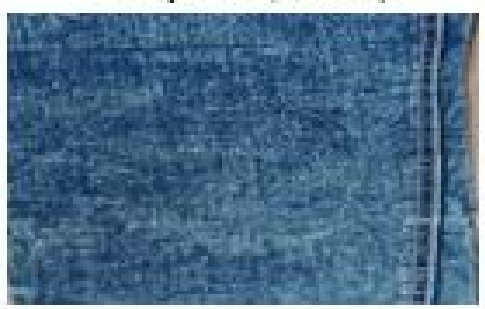

Acid (Stone)

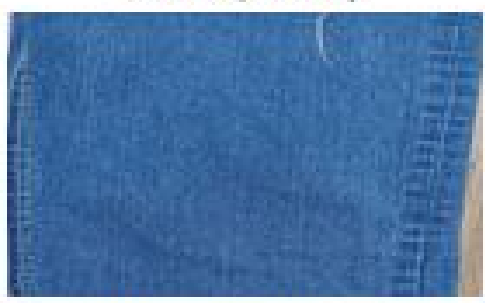

Bleach (Stone)

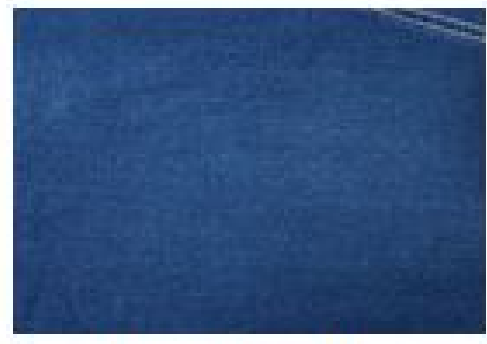

Enzyme (Sole)

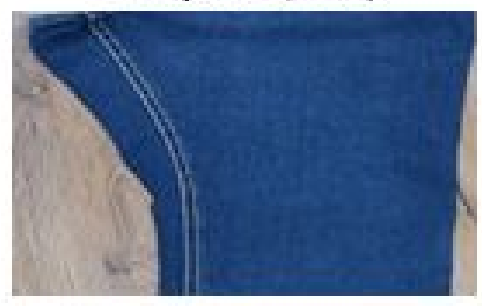

Acid (Sole)

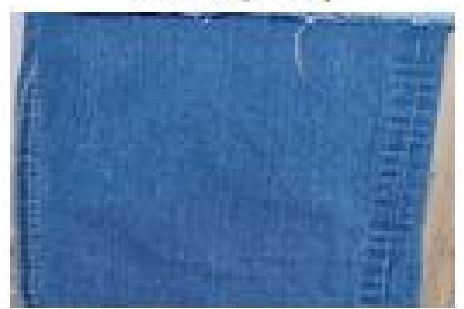

Bleach (Sole)

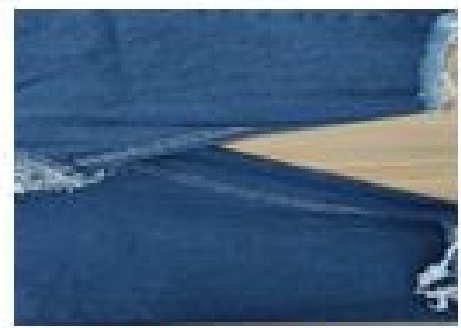

Stone vs. Sole

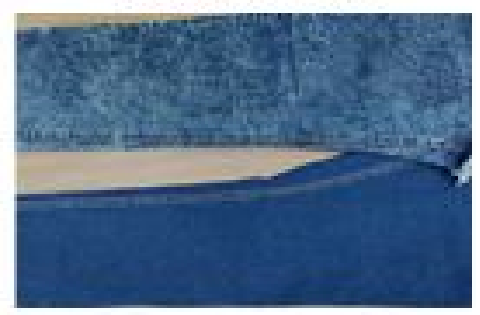

Stone vs. Sole

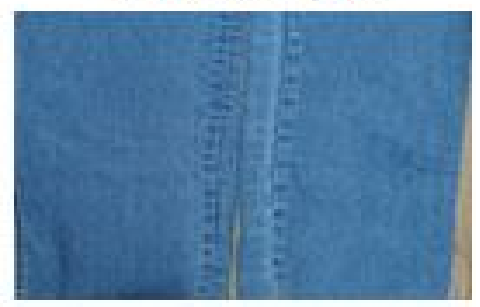

Stone vs. Sole

Fig 2. Visual assessments of all washed denim fabrics

From below the pictorial view (Figure 2), it can be concluded that there is a very subtle difference among all the samples. According to the washing experts, a new faded look (wash effect) has been found by shoe soles, which can attract buyers more if they consider sustainable issues. Since diverse faded looks are optimum aspiration to the young people, so without any doubt, it can fulfill the cherished requirement. Over against, sustainable issues will be maintained narrowly in denim washing.

\subsection{Tensile strength (Breaking strength)}

The tensile strength of washed fabric samples along with the original one is shown in Figure 3 . A tensile test is the measurement of the force required when a specimen responds to stress. Tensile strength is the ruptured force which is directly proportional to the cross-sectional area ${ }^{(25)}$. In this result, which fabric is washed by shoe sole instead of stone, that fabric creates an extra force to elongate except enzyme wash. However, a Maximum of $1193 \mathrm{~N}$ is found for bleach (sole) and at least $1052 \mathrm{~N}$ for the enzyme (sole) in the warp direction, whereas other magnitudes are in the mediatory. It happens for losing fibers with the action of stone on cellulosic fabrics. In enzyme wash, it happened opposite things due to enzymatic action on cellulosic fibers. Conversely, a presidential value $313 \mathrm{~N}$ is for acid washing (sole) and similarly, the least value appears $234 \mathrm{~N}$ for acid (stone), which has come for tension release due to wet treatment. And one thing is mentionable that warp yarn needs extra force to elongate then weft yarn because of more yarn in per unit length. 


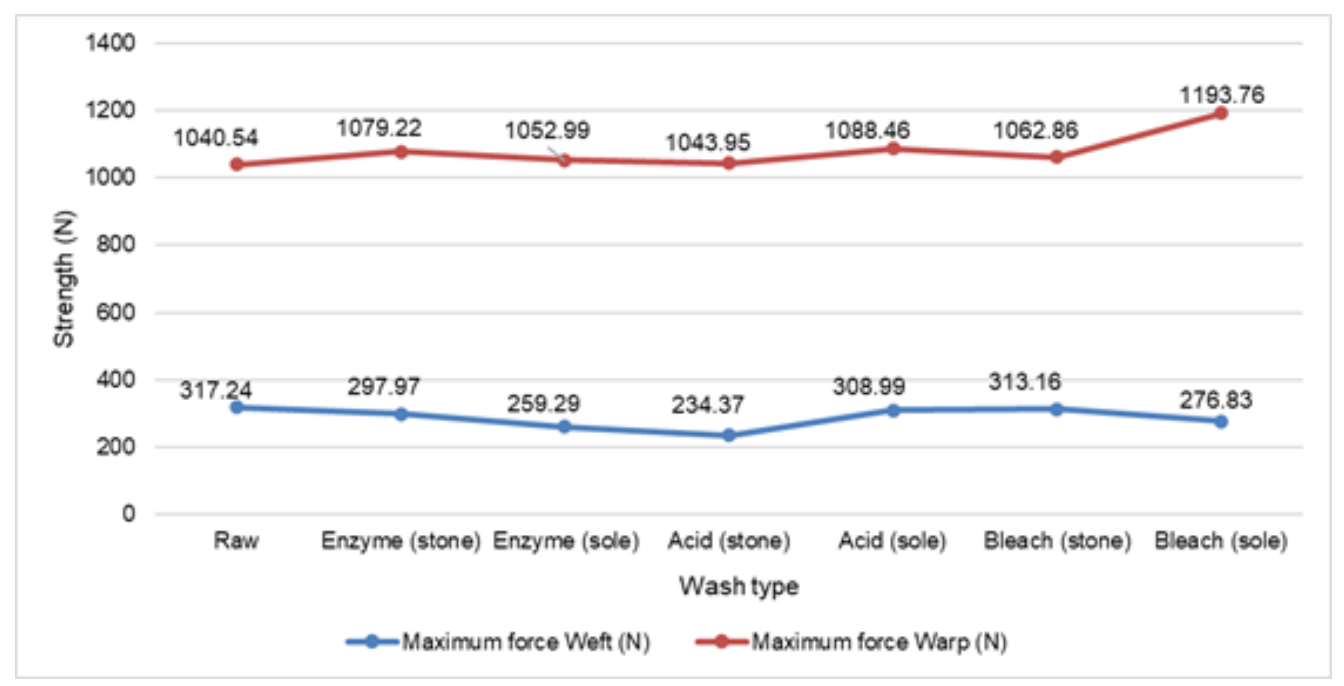

Fig 3. Tensile strength of washed denim fabrics

\subsection{Tear strength}

Figure 4 represents the tear strength in warp and weft direction of washed specimens, using different washing procedures. Here, the tear strength of unwashed raw denim is more compared to others in both directions. Ideally, tear strength is high for bleach wash with sole and it is almost $45 \mathrm{~N}$, and gradually decreasing to near $25 \mathrm{~N}$ for acid washing in the warp. On the other side $23.78 \mathrm{~N}$ for the bleach with the sole which also shows the least strength $22 \mathrm{~N}$ for acid washing with the stone in the weft direction, which is with sole in warp But in the tear test which fabric is washed by shoe sole instead of stone, that fabric creates an extra force to tear except acid wash. In the acid wash, it happened opposite things.

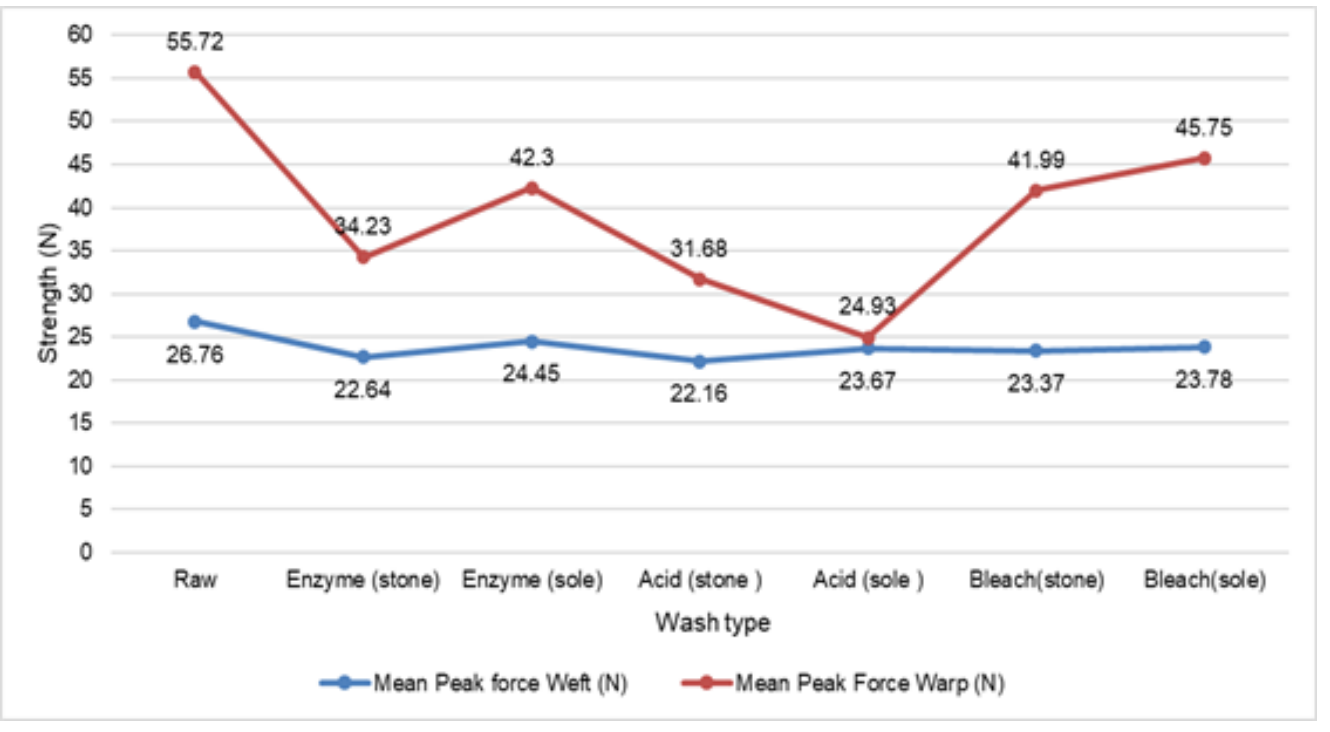

Fig 4. Tear strength of washed denim fabrics

\subsection{Mass per unit area (GSM)}

The following Figure 5 depicts the GSM changes after washing. Since the warp yarn is subjected to considerable strength during weaving and after relaxation it reduces in both directions, washing procedure influences the mass per unit area. GSM of washed samples increased by almost $2.5 \%-5 \%$ compared to raw denim. Also, the graph indicates the maximum GSM of acid (sole) and 
minimum for the enzyme (sole), and following GSM of Enzyme (stone) greater than Enzyme (sole), GSM of Acid (stone) lower than GSM of Acid (sole) and GSM of Bleach (stone) are equal with Bleach (sole).

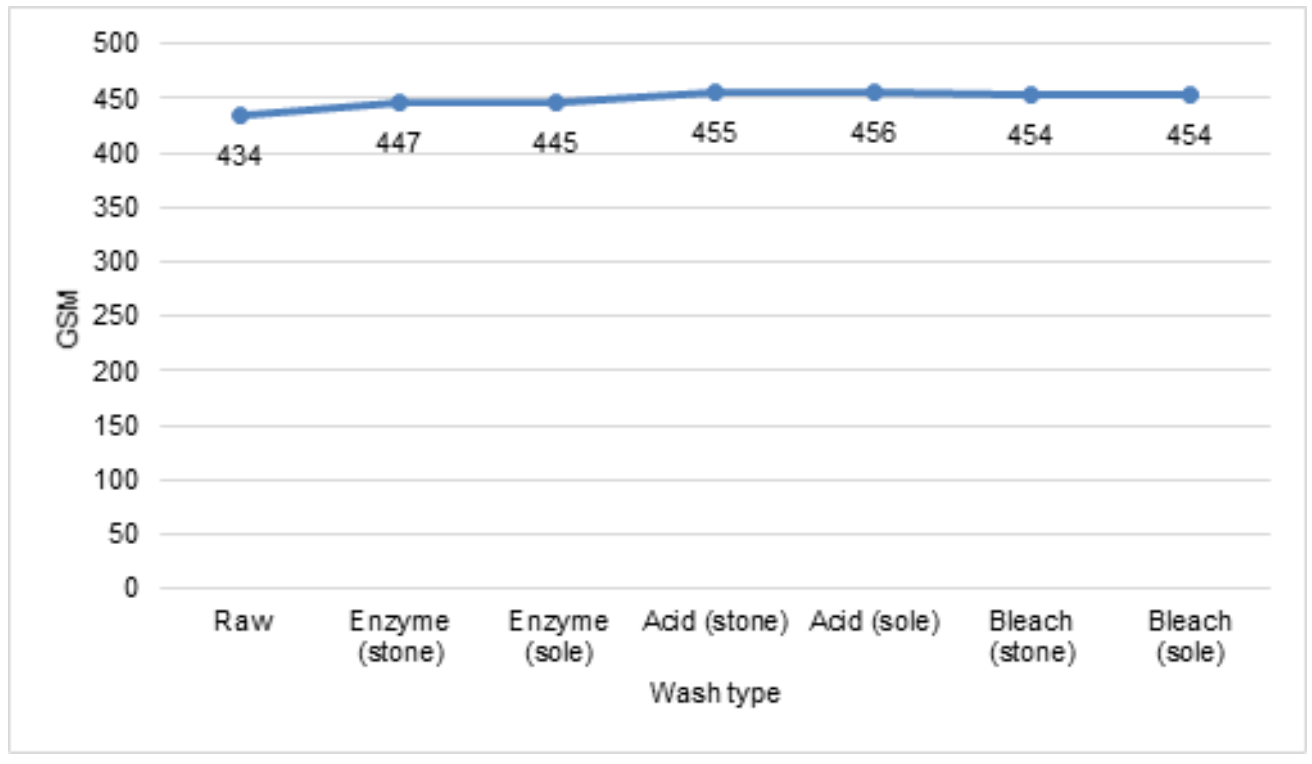

Fig 5. Fabric weight per unit area of washed denim fabrics

\subsection{Abrasion resistance}

Figure 6 represents the changes of weight loss due to abrasion. The abrasion resistance was determined by the mass loss as the difference between the masses before and after abrasion cycles of 2500, 5000, 7500, and 10000. Overall values show the amount of weight loss is less for sole compared to stone wash. The graph shows the maximum weight loss for both washing procedures acid (stone) and bleach (stone) whilst the minimum weight loss is noticed for bleach (sole) washed samples. The reason behind not affecting surface characteristics for using shoe sole of stone.

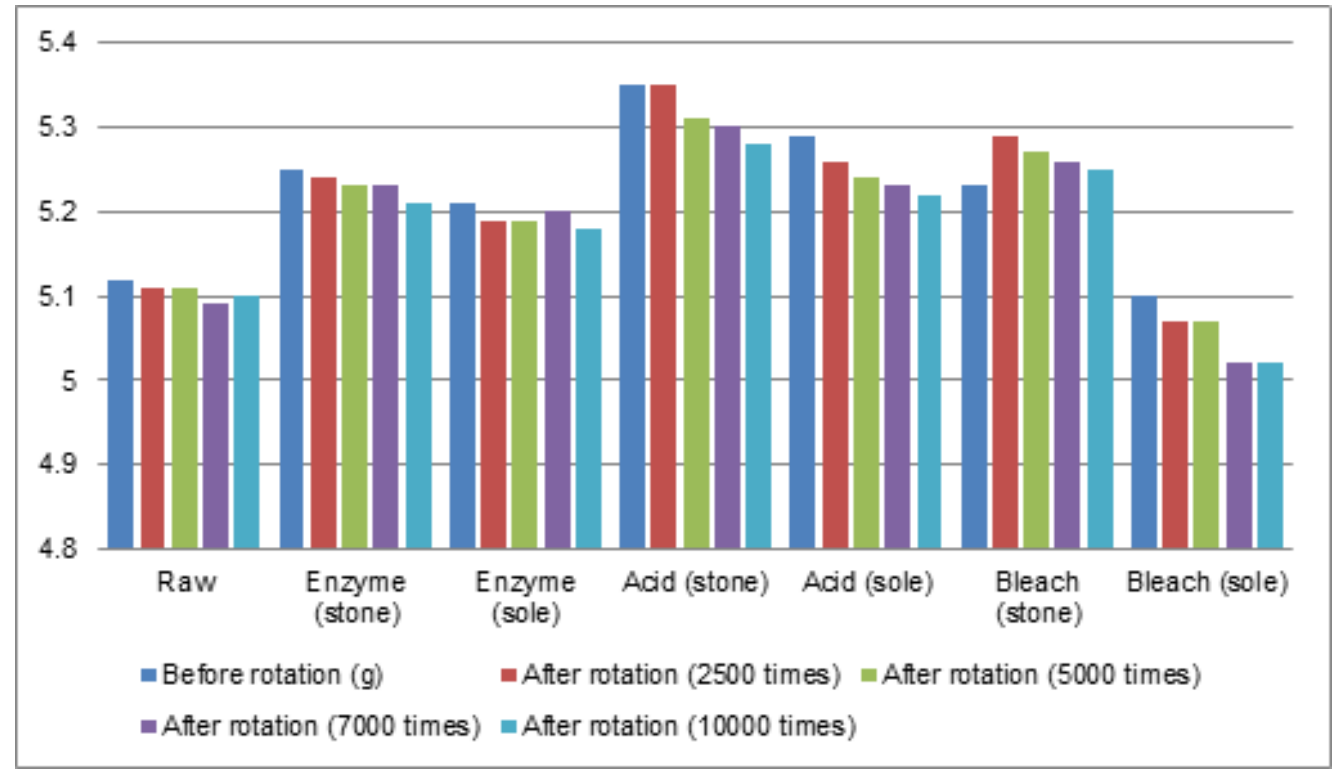

Fig 6. Fabric weight loss by abrasion of washed denim fabrics 


\subsection{Crimp interchange (warp and weft way)}

Crimp percentage refers to when warp and weft yarns interlace in the fabric they follow a wavy or corrugated path, crimp percentage delineates in Figure 7 is a measure of this waviness in yarns. From this figure, it is found that the crimp percentage of the warp is less than weft. In short, weft yarn gains more waviness for acid wash respectively about 21 percent for the sole and approximately 14 percent for the stonewash. Thereafter, warp yarns gain the same result respectively 15 and 11 percent waviness. But the least result has been found was enzyme washing with the sole. It is because the warp yarns are kept in tension during weaving. Besides, they are usually stronger and better yarn than weft. So they do not extend more. On the other hand, weft yarns are kept in low tension and low in quality. So they can extend more. As a result, their crimp percentage is more.

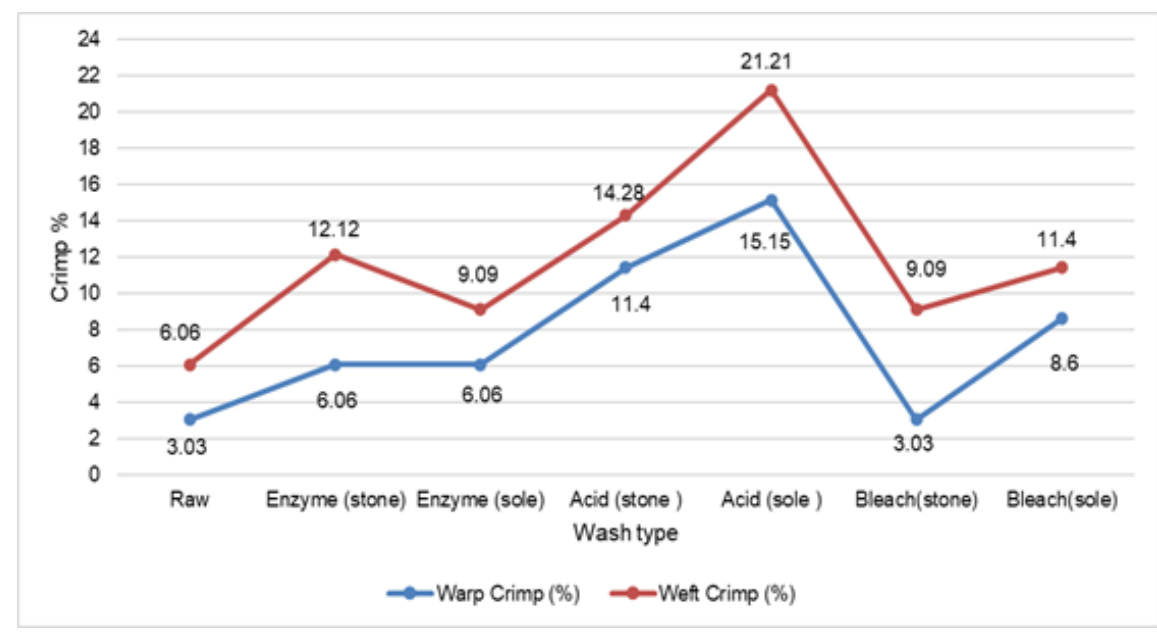

Fig 7. Crimp percentage values (warp and weft way) of washed denim fabrics

\subsection{Fabric count}

The horizontal axis of the following Figure 8 denotes the washing names of fabrics, and also the vertical axis denotes the Ends per inch (EPI), Picks per inch (PPI) values as well. In contrast, a maximum of 111 yarn per inch has been found in warp direction for sole enzymatic treatment and gradually decreasing to the beach to acid. Also, a maximum of 58 PPI appears for bleach wash which slightly decreases to 54 for an acid wash in the weft direction. Due to the wash variants, both the magnitude has been changed slightly which can support an acceptable shrinkage percentage.

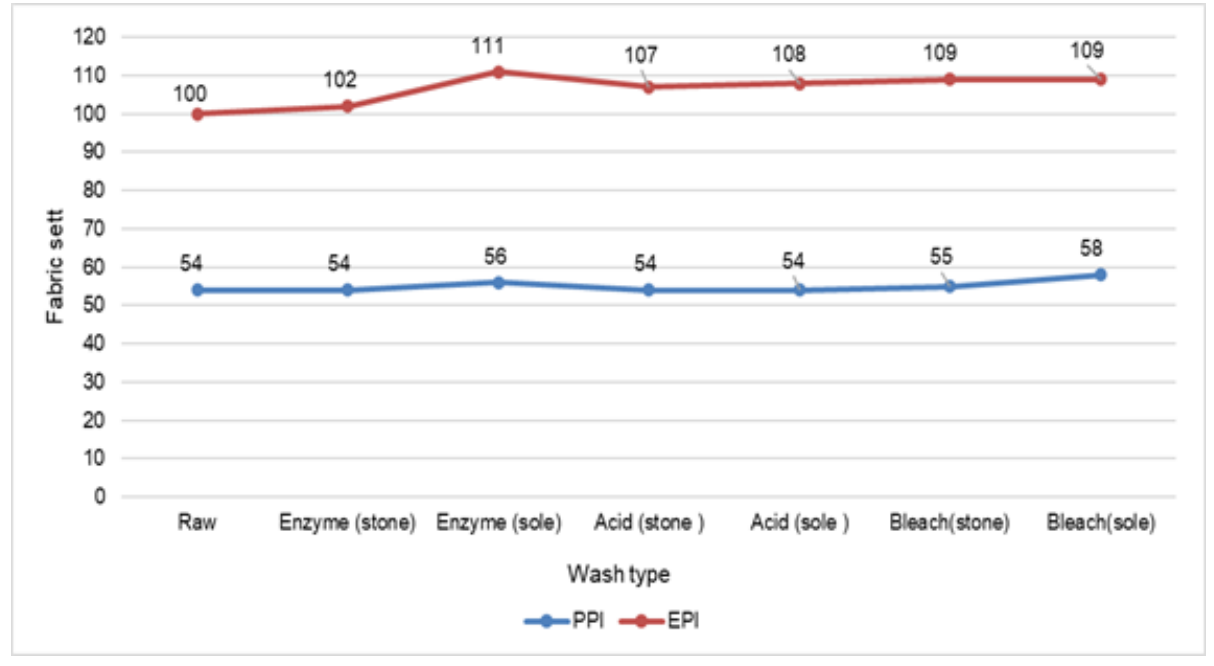

Fig 8. Fabric sett of washed denim fabrics 


\subsection{Noise intensity}

Figure 9, shows that the noise intensity is caused by washing. Here, stone washing (With enzyme, Acid, and Bleach) always gives the highest value compared to shoe soles. Corresponding figures show stone washing value near about $89.5 \mathrm{~dB}$, whereas sole washing magnitude is almost $21 \mathrm{~dB}$ less, to be more exact $68 \mathrm{~dB}$. It comes due to friction between stone (rock salt) and washing machine. So washing by shoe sole brings a quiescence environment for the worker and responsible person as well. Here, it is mentionable that sound intensity has been measured directly by a smartphone with a convenient smart application.

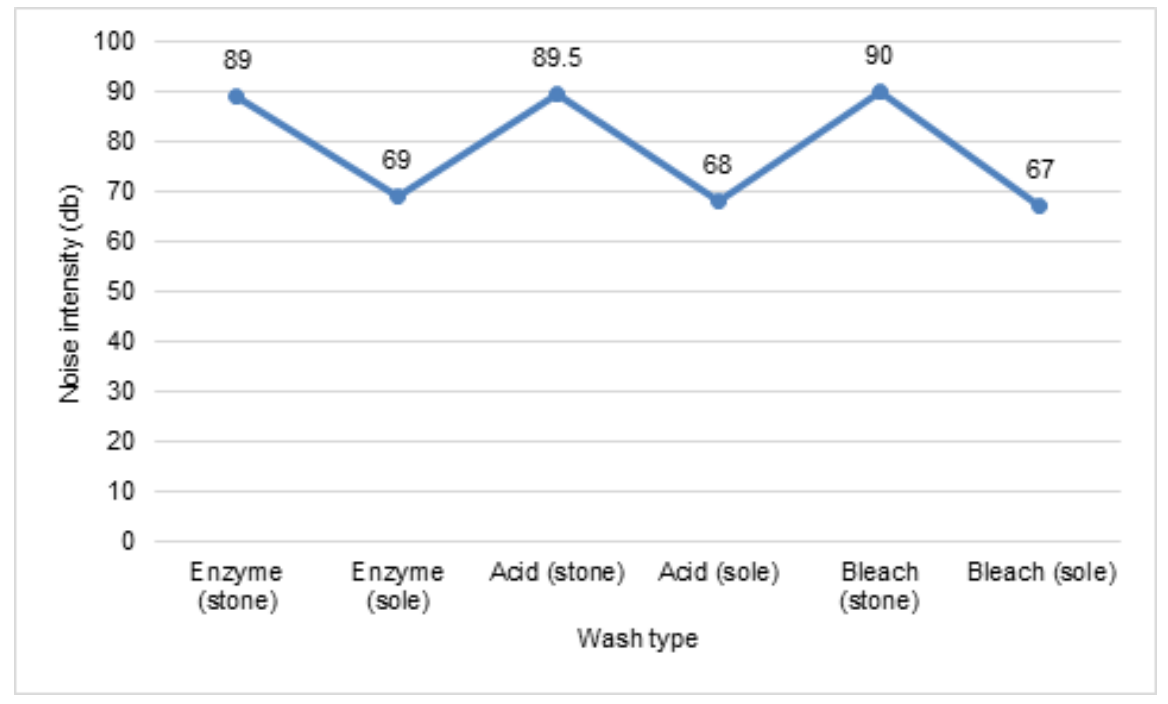

Fig 9. Noise intensity due to washing

\section{Conclusion}

The above discussion reveals that washing is an essential finishing in the denim industry which enhances fading effects along with softness and comfort, but it is the single most environmentally polluting industry in the fashion market. Averring that, producers cannot enforce individually without the collaborating supports of retailers. In this cornerstone, a post-used rubber shoe sole can be used to mitigate the adverse effects on nature, since the shoe sole provides similar fabric characteristics to a stonewash. Introducing the aforementioned alternative in denim washing, it shows the perfect results rather than stone one without compromising the trendy looks. Explicitly, a wash technician found another shade that can attract buyers more. Also, the minimum noise level has been experienced in this work. And hence, it can be concluded post-used rubber shoe sole would be effective for washing.

\section{Conflicting interests}

The author(s) declared no potential conflicts of interest concerning the research, authorship, and/or publication of this article.

\section{Funding}

The author(s) received no financial support for the research, authorship, and/or publication of this article.

\section{References}

1) Alam R, Islam T, Haider A, Haque N, Islam J, Zakaria M. Development of Double Cloth Structure to Facilitate Versatile Application of Denim Fabric. Journal of Textile Science and Technology. 2019;05(01):19-26. Available from: https://dx.doi.org/10.4236/jtst.2019.51002.

2) Periyasamy A, Ramamoorthy P, Sunil K, Lavate, Saatish S. Eco-friendly Denim Processing. In: Martínez L, Kharissova O, Kharisov B, editors. Handbook of Ecomaterials. Cham. Springer. 2019;p. 1559-1579. Available from: https://doi.org/10.1007/978-3-319-68255-6_102.

3) Khalil E. Investigation of the Influence of Potassium Permanganate on Denim Jeans Processing During Acid Wash. American Association for Science and Technology. 2015;2(6):271-275. Available from: https://doi.org/10.5281/zenodo.31939.

4) Ansari IZ. Impact of Stone Wash and Acid Wash on the Physical Properties of Denim. International Journal of Engineering Research. 2017;6(12):499. Available from: https://dx.doi.org/10.5958/2319-6890.2017.00073.3. 
5) Sarkar J, Khalil E, Solaiman M. Effect of Enzyme Washing Combined With Pumice Stone on the Physical, Mechanical and Color Properties of Denim Garments. International Journal of Research in Advent Technology. 2014;2(9):2321-9637. Available from: https://doi.org/10.6084/M9.FIGSHARE.1424473.

6) Hafeezullah M, Ali NK, Buying W, Chengyan ZHU. Effect of different types of washing processes on the strength and weight loss of the Denim fabric. Asia-Africa Science Platform Program on Neo-fiber Technology Seminar Series. 2014;9:1-2. Available from: https://doi.org/10.13140/RG.2.1.1117.1042.

7) Arjun D, Hiranmayee J, Farheen MN. Technology of Industrial Denim Washing: Review. International Journal of Industrial Engineering and Technology. 2013;3(4):25-34.

8) Hoque M, Rashid S, Muhammad A, Chowdhury S, Chakraborty A, Haque A, et al. Alternative Washing of Cotton Denim Fabrics by Natural Agents. American Journal of Environmental Protection. 2018;7(6):79-83. Available from: https://doi.org/10.11648/j.ajep.20180706.12.

9) Khalil E, Sarkar J, Rahman M, Solaiman M. Influence of Enzyme and Silicone Wash on the Physico-Mechanical Properties of Non-Denim Twill Garments. International Journal of Scientific and Technology Research. 2014;3(10):231-233.

10) Munna M, Chinyerenwa KH, Adindu C, Hossain AM, Rumi MT. The Effect of Natural Reducing Agents on Denim Fabric for the Amelioration of Natural Fading Effect via Environmental Friendly Approach. Science Research. 2016;4(6):146-152. Available from: https://doi.org/10.11648/j.sr.20160406.11.

11) Csanák E. Sustainable concepts and Eco-Friendly technologies in the Denim industry. In: International Conference on Design and Light Industry Technologies. Budapest, Hungary. Óbuda University. 2014;p. 1-6. Available from: https://doi.org/10.13140/RG.2.1.3783.0484.

12) Choudhury AKR. 12-Finishing of denim fabrics. In: and others, editor. Principles of Textile Finishing. Woodhead Publishing Series in Textiles. 2017;p. 383-415.

13) Khan MMR, Mondal MIH, Uddin MZ. Sustainable washing for denim garments by enzymatic treatment. Journal of Chemical Engineering. 2013;27(1):2731. Available from: https://dx.doi.org/10.3329/jce.v27i1.15854.

14) Soon W, Baliunas SL, Robinson AB, Robinson ZW. Environmental effects of increased atmospheric carbon dioxide. Climate Research. 1999;13(2):149-164. Available from: https://dx.doi.org/10.3354/cr013149.

15) Florides GA, Christodoulides P. Global warming and carbon dioxide through sciences. Environment International. 2009;35(2):390-401. Available from: https://dx.doi.org/10.1016/j.envint.2008.07.007.

16) Zhong W, Haigh JD. The greenhouse effect and carbon dioxide. Weather. 2013;68(4):100-105. Available from: https://dx.doi.org/10.1002/wea.2072.

17) ASTM D1776, Standard Practice for Conditioning and Testing Textiles, Developed by Subcommittee: D13.51, Book of Standards. . Available from: https://www.astm.org/Standards/D1776.html.

18) 5034 AD. ASTM D 5034, Standard Test Method for Breaking Strength and Elongation of Textile Fabrics (Grab Test), Developed by Subcommittee: D13.60, Book of Standards. . Available from: https://www.astm.org/Standards/D5034.htm.

19) D1424 A. ASTM D1424, Standard Test Method for Tearing Strength of Fabrics by Falling-Pendulum (Elmendorf-Type) Apparatus, Developed by Subcommittee: D13.60, Book of Standards . . Available from: https://www.astm.org/Standards/D1424.html.

20) AATCC-61, AATCC 61 Method 2A-Colorfastness, https://www.aatcc.org/testing/methods/. . Available from: https:/www.aatcc.org/testing/methods/.

21) D3776 A. ASTM D3776, Standard Test Methods for Mass per Unit Area (Weight) of Fabric, Developed by Subcommittee: D13.60, Book of Standards. . Available from: https://www.astm.org/Standards/D3776.htm.

22) ASTM D 4966-98, Standard Test Method for Abrasion Resistance of Textile Fabrics (Martindale Abrasion Tester Method). Martindale Abrasion Tester Method. . Available from: https://www.astm.org/DATABASE.CART/HISTORICAL/D4966-98R04.html.

23) ASTM D 3883, Standard Test Method for Yarn Crimp and Yarn Take-up in Woven Fabrics, Developed by Subcommittee: D13.59, Book of Standards. . Available from: https://www.astm.org/Standards/D3883.html.

24) ASTM D 3775-08, Standard Test Method for Warp (End) and Filling (Pick) Count of Woven Fabrics. . Available from: https://www.astm.org/DATABASE. CART/HISTORICAL/D3775-08.html.

25) Hossain MM. A Review on Different Factors of Woven Fabrics' Strength Prediction. Scientific Research. 2016;4(3):88-97. Available from: https: //doi.org/10.11648/j.sr.20160403.13. 